\title{
Effects of median nerve block on radial artery diameter and peak velocity
}

\author{
This article was published in the following Dove Press journal: \\ Local and Regional Anesthesia \\ 16 February 2010 \\ Number of times this article has been viewed
}

\author{
John J Badal \\ Annie Kiesau \\ Patrick Boyle \\ University of Arizona, Department \\ of Anesthesiology, Tucson, AZ, USA
}

Correspondence: John J Badal

University Medical Center, Department

of Anesthesiology, Room 530I, I50I N

Campbell Ave, Tucson AZ, 85724, USA

Tel +52027 I 6546

Fax +5206266943

Email jjbadal@yahoo.com

\begin{abstract}
Peripheral artery cannulation is a common procedure but can sometimes be difficult. Our goal was to determine if a median nerve block would increase the diameter and flow of the radial artery. Radial artery diameter and peak velocity was measured using a SonoSite Ultrasound System. Using ultrasound guidance, a median nerve block was performed with lidocaine. Subsequent measurements of the radial artery and peak velocity were again made at 5 minutes post-block and 10 minutes post-block. Mean radial artery diameter measured vertically was $0.23 \pm 0.06 \mathrm{~cm}$ pre-block, $0.23 \pm 0.05 \mathrm{~cm}$ at 5 minutes post-block, and $0.23 \pm 0.05 \mathrm{~cm}$ 10 minutes post-block. Mean radial artery diameter measured horizontally was $0.26 \pm 0.05 \mathrm{~cm}$ pre-block, $0.27 \pm 0.06 \mathrm{~cm}$ at 5 minutes post-block, and $0.27 \pm 0.08 \mathrm{~cm} 10$ minutes post-block. Peak velocities were $11.3 \pm 6.9 \mathrm{~cm} / \mathrm{s}$ pre-block, increased to $15.0 \pm 6.9 \mathrm{~cm} / \mathrm{s} 5$ minutes postblock $(P=0.005)$, and finally increased to $17.7 \pm 7.8 \mathrm{~cm} / \mathrm{s} 10$ minutes post-block $(P=0.01)$. This study set out to measure the effects of median nerve blockade on the radial artery. We found a significant increase in peak velocities post-median nerve blockade.
\end{abstract}

Keywords: radial artery, median nerve block, sympathetic

\section{Introduction}

Peripheral artery cannulation is a common procedure performed for continuous blood pressure monitoring and rapid access for collecting blood for various laboratory studies. It is frequently needed for patients undergoing cardiac, vascular, and major surgeries, and is required in many trauma settings as well. The radial artery is most commonly used because of ease of access and low risk of complications. However, placement of a radial artery catheter can be difficult because many patients who need a catheter may have weak pulses, are dehydrated, or have some form of peripheral vascular disease. Although it is usually a well-tolerated procedure, it is considered more painful than IV placement and is made worse by multiple attempts.

It has already been established that inhibition of sympathetic innervation decreases vasomotor activity in muscular arteries, ${ }^{1-3}$ and that axillary nerve blockade increases blood flow to the radial artery. ${ }^{4,5}$ Thus, the sympathetic nerves that supply the radial artery travel with the brachial plexus at least to the level of the axillary artery, but beyond that, the pathway of sympathetic innervation to the radial artery is unknown. The median nerve may play an integral part in control of radial artery vasoconstriction and vasodilatation.

Our goal was to determine if a median nerve block using lidocaine would increase the diameter and flow of the radial artery by blocking its sympathetic innervation, thus facilitating arterial catheter placement. 


\section{Methods}

After institutional review board approval, eight subjects undergoing surgery who required arterial catheter placement prior to induction of anesthesia consented and were enrolled in this experimental study. Minors, emergency surgical patients, pregnant patients, and those with a language barrier were excluded. In addition, any patient with neurological symptoms of the upper extremity was excluded.

Each subject had a peripheral IV placed and all subjects were monitored with a pulse oximeter and intermittent noninvasive blood pressure recordings on the opposite arm. They were given 2 liters of oxygen via a nasal cannula, and received a standard dose of midazolam (2 $\mathrm{mg})$ or fentanyl (50 mcg) in the pre-operative holding area. A mark was made $1 \mathrm{~cm}$ proximal to the styloid process to provide consistency with all measurements taken. Radial artery diameter was measured in two planes (horizontal and vertical) using a SonoSite Ultrasound System (MicroMaxx ${ }^{\mathrm{TM}}$, P05353-01) (Figure 1). Next, the peak velocity was measured at the same position using the Doppler mode on the Sonosite probe (Figure 2). The measurement taken was the highest point on the first four waveforms seen. Next, using ultrasound guidance, the median nerve was identified medial to the brachial artery on the anterior elbow (Figure 3), and $5 \mathrm{ml}$ of $2 \%$ lidocaine were injected into the fascial planes surrounding the median nerve using a 25 gauge needle (Figure 4). If pain was noted on injection, the needle was withdrawn and redirected. Aspiration for blood was performed prior to injection to prevent vascular administration.

The success of median nerve blockade was assessed by confirming decreased sensation and weakness in the distribution of the median nerve. Subsequent measurements of the radial artery and peak velocity as described above were made using the ultrasound probe at 5 minutes post-block and 10 minutes post-block. An arterial line was then placed in the usual fashion using a standard Arrow kit, which concluded the subject's participation in this study.

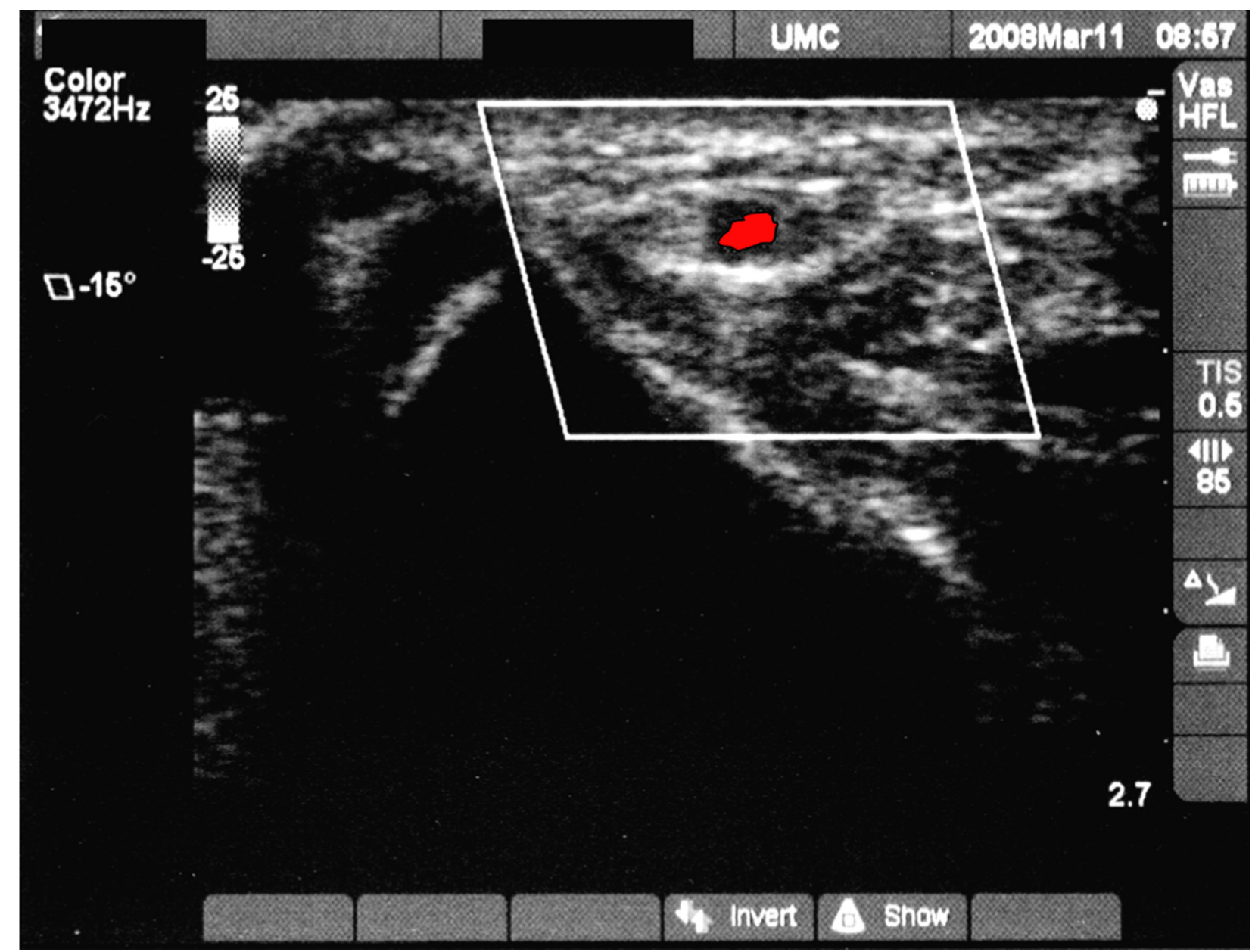

Figure I Ultrasound view of radial artery. 


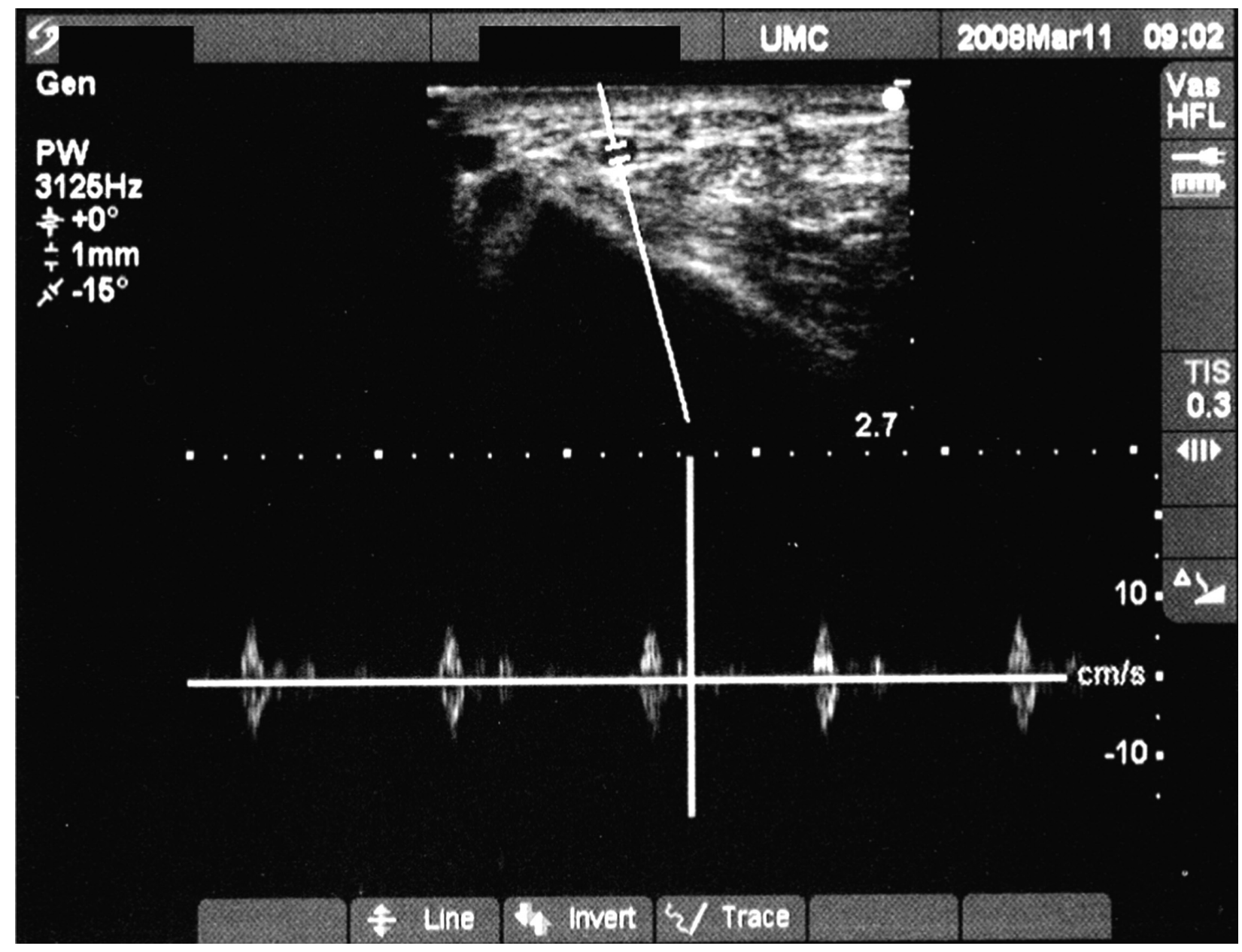

Figure 2 Doppler tracing of radial artery for peak velocity measurements.

\section{Results}

Eight subjects were enrolled in this study. Subjects' age range was from 46-81 years, with a mean age of 64. Six were female, 2 were male. Co-morbidities included coronary artery disease (5), history of smoking (5), hypertension (3), diabetes mellitus (3), cancer (2), atrial fibrillation (1), aortic stenosis (1), and transient ischemic attacks (1). All eight subjects had successful median nerve blockade by exam. All data was analyzed using Paired Student's T-Test.

Mean radial artery diameter measured vertically was $0.23 \pm 0.06 \mathrm{~cm}$ pre-block, $0.23 \pm 0.05 \mathrm{~cm}$ at 5 minutes postblock and $0.23 \pm 0.05 \mathrm{~cm} 10$ minutes post-block. $P$-value from pre-block to 5 minutes post-block was 0.92 , from 5 minutes post-block to 10 minutes post-block was 0.43 , and from pre-block to 10 minutes post-block was 0.69 .

Mean radial artery diameter measured horizontally was $0.26 \pm 0.05 \mathrm{~cm}$ pre-block, $0.27 \pm 0.06 \mathrm{~cm}$ at 5 minutes postblock and $0.27 \pm 0.08 \mathrm{~cm} 10$ minutes post-block. $P$-value from pre-block to 5 minutes post-block was 0.16 , from
5 minutes post-block to 10 minutes post-block was 0.82 , and from pre-block to 10 minutes post-block was 0.37 .

Peak velocities were $11.3 \pm 6.9 \mathrm{~cm} / \mathrm{s}$ pre-block, increased to $15.0 \pm 6.9 \mathrm{~cm} / \mathrm{s} 5$ minutes post-block $(P=0.005)$, and finally increased to $17.7 \pm 7.8 \mathrm{~cm} / \mathrm{s} 10$ minutes post-block (0.01) (Figure 5). There was no significant change in velocity between 5 minutes post-block and 10 minutes post-block $(P=0.17)$.

\section{Discussion}

According to our data, there is no statistical difference between radial artery diameter (measured either in the vertical direction or in the horizontal direction) after medial nerve blockade. There is, however, a significant increase in peak velocity measured pre and post-blockade. It seems that the greatest effects of median nerve blockade occur within 5 minutes of the block given that pre-block velocities were $11.3 \pm 6.9 \mathrm{~cm} / \mathrm{s}$ and increased to $15.0 \pm$ $6.9 \mathrm{~cm} / \mathrm{s} 5$ minutes post-block $(P=0.005)$. The increase 


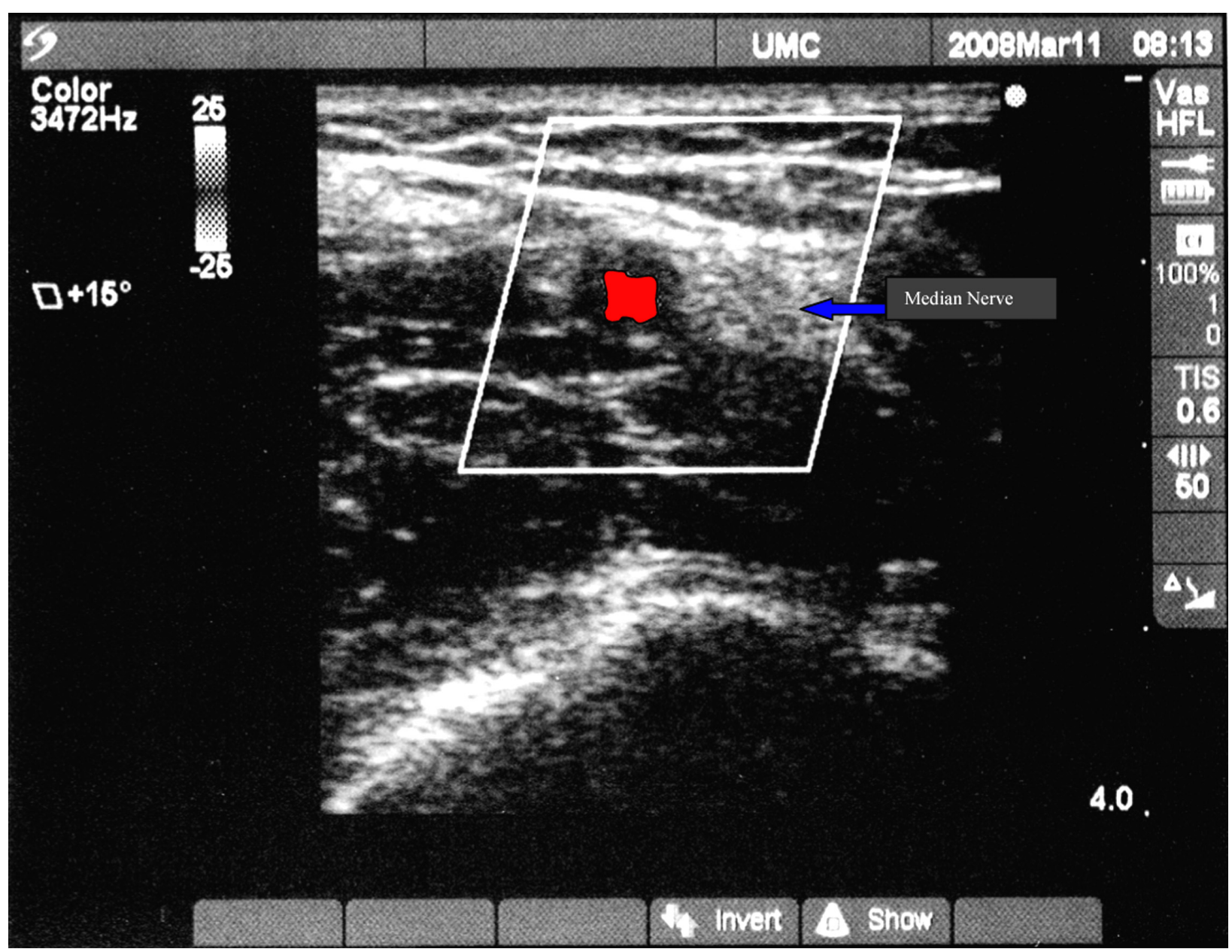

Figure 3 Ultrasound view of brachial artery with median nerve to reader's right.

from 5 minutes post-block to 10 minutes post-block is not statistically significant $(15.0 \pm 6.9 \mathrm{~cm} / \mathrm{s}$ and $17.7 \pm 7.8 \mathrm{~cm} / \mathrm{s}$ respectively, $P=0.17)$. It is unclear whether the increase in velocity would be an advantage during arterial line placement. Anecdotally, there was a dramatic increase in ability to palpate the radial pulse post-blockade. In most subjects, the radial artery was easily palpable up to the antecubital fossa post-blockade. This was an unexpected finding and was not quantified or qualified. It would be interesting to place median nerve blocks in patients with poorly palpable, or un-palpable radial arteries to assist in finding the artery. This is potential area of future research.

Another interesting and unexpected finding was that after introduction of the arterial catheter into the artery, it was a challenge to thread the guide wire before blood spilled from the top of the Arrow kit. None of the researchers had experienced this in the past and it was speculated that this was related to the increase in peak velocities. Yet another unexpected finding was the degree of subject comfort. We are very familiar with the grimaces and groans from our patients while placing an arterial line, but there was little evidence of subject discomfort in any of our arterial line attempts for this study. We believe this was due to the profound anesthesia that a median nerve block provided over this area.

A limitation of this study was the small sample size of only 8 subjects. Furthermore, 7 of the 8 subjects had risk factors for peripheral vascular disease ( 5 had coronary artery disease, 5 had a history of smoking, 3 had hypertension, and 1 had diabetes mellitus). It is uncertain whether subjects' arteries are able to measurably dilate if they do indeed have significant peripheral vascular disease. A future study should be done with healthy subjects as a comparison.

This study set out to measure the effects of median nerve blockade on the radial artery. A significant increase in peak velocities post-median nerve blockade was found.

\section{Disclosures}

The authors report no conflicts of interest in this work. 


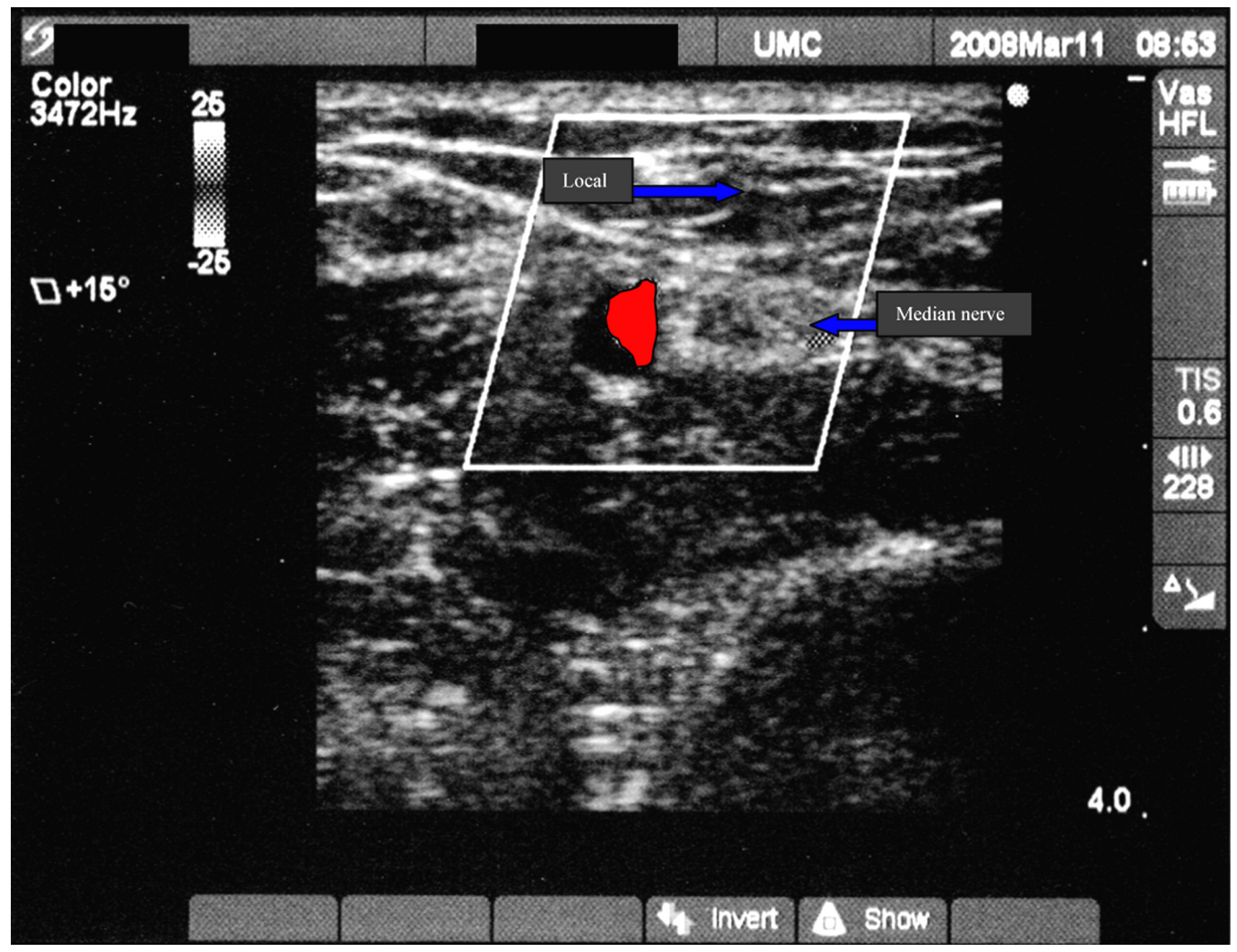

Figure 4 Lidocaine infiltration around median nerve.

Mean radial artery peak velocities

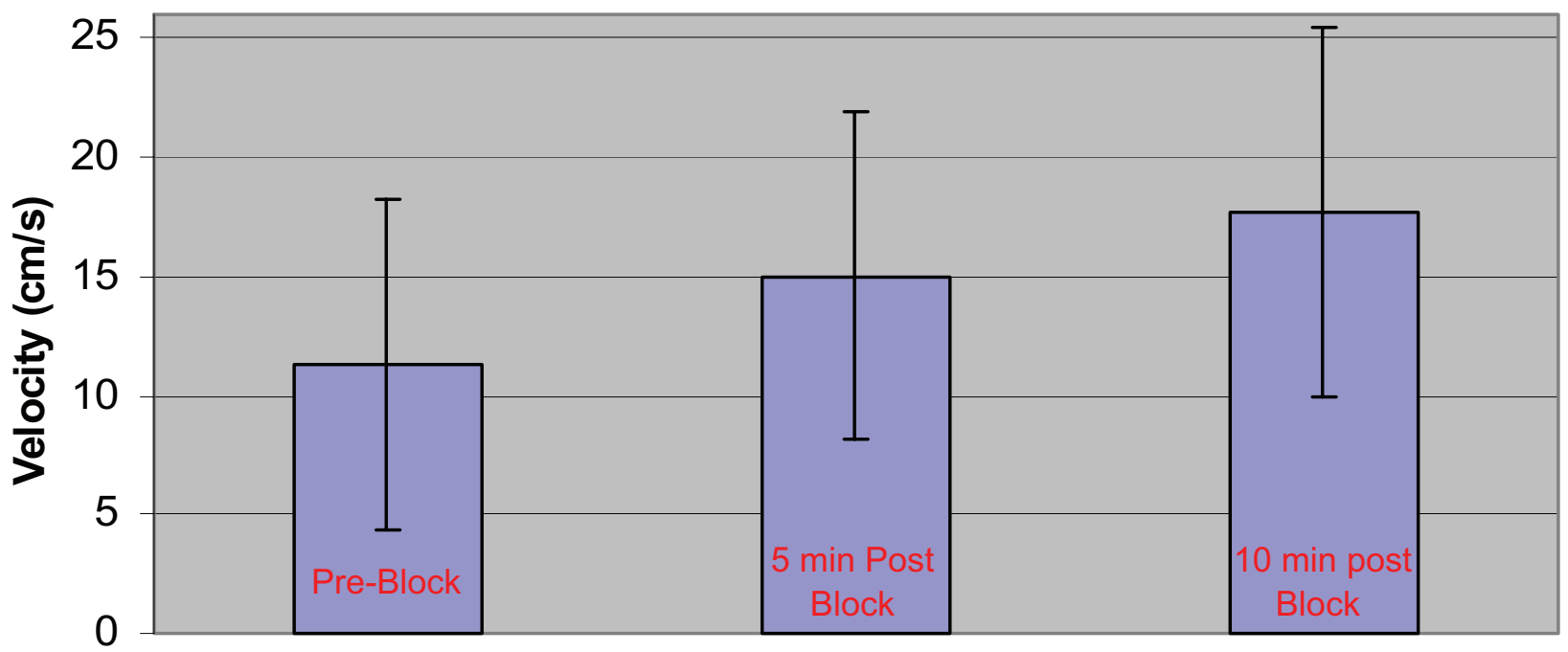

Figure $\mathbf{5}$ Mean radial artery peak velocities with error bars. 


\section{References}

1. Ebert B, Braunschweig R, Reill P. Quantification of variations in arm perfusion after plexus anesthesia with color doppler sonography. Anaesthesist. 1995;44(12):859-862.

2. Iskandar H, Wakim N, Benard A, et al. The effects of interscalene brachial plexus block on humeral arterial blood flow: a Doppler ultrasound study. Anesth Analg. 2005;101:279-281.

3. Lindqvist M, Davidson S, Hjemdahl P, Melcher A. Sustained forearm vasodilation in humans during mental stress is not neurogenically mediated. Acta Physiol Scand. 1996;158(1):7-14.
4. Breschan C, Kraschl R, Jost R, Marhofer P, Likar R. Axillary brachial plexus block for treatment of severe forearm ischemia after arterial cannulation in an extremely low birth-weight infant. Paediatr Anaesth. 2004;14(8):681-684.

5. Mehta Y, Jeneja R. Continuous axillary block for ischemia following failed radial artery cannulation. J Cardiothorac Vasc Anesth. 1994;8(2):257.

\section{Publish your work in this journal}

Local and Regional Anesthesia is an international, peer-reviewed, open access journal publishing on the development, pharmacology, delivery and targeting and clinical use of local and regional anesthetics and analgesics. The journal welcomes submitted papers covering original research, basic science, clinical studies, reviews \& evaluations, guidelines, expert opinion and commentary, case reports and extended reports. The manuscript management system is completely online and includes a very quick and fair peer-review system, which is all easy to use. Visit http://www.dovepress.com/testimonials.php to read real quotes from published authors. 